\title{
One single dose of histidine-tryptophan-ketoglutarate solution gives equally good myocardial protection in elective mitral valve surgery as repetitive cold blood cardioplegia: A prospective randomized study
}

\author{
Bjørn Braathen, MD, ${ }^{\text {a }}$ Anders Jeppsson, MD, PhD,${ }^{\text {b,c }}$ Henrik Scherstén, MD, PhD, ${ }^{\text {b,c }}$ Ole M. Hagen, MD, ${ }^{a}$ \\ Øystein Vengen, MD, PhD, ${ }^{a}$ Helena Rexius, MD, PhD, ${ }^{\mathrm{b}, \mathrm{c}}$ Vincenzo Lepore, $\mathrm{MD}, \mathrm{PhD},{ }^{\mathrm{b}, \mathrm{c}}$ and \\ Theis Tønnessen, MD, $\mathrm{PhD}^{\mathrm{a}, \mathrm{d}}$
}

\begin{abstract}
Objectives: Histidine-tryptophan-ketoglutarate (HTK-Custodiol) cardioplegic solution is administered as one single dose for more than 2 hours of ischemia. No prospective randomized clinical study has compared the effects of HTK and cold blood cardioplegia on myocardial damage in elective mitral valve surgery. Thus, the main aim of the present study was to examine whether one single dose of cold antegrade HTK gives as good myocardial protection as repetitive antegrade cold blood cardioplegia in mitral valve surgery.
\end{abstract}

\begin{abstract}
Methods: Eighty consecutive patients undergoing elective isolated mitral valve surgery for mitral regurgitation, with or without ablation for atrial fibrillation, were included in the study and randomized to HTK or blood cardioplegia. Markers of myocardial injury (troponin-T and creatine kinase MB) were analyzed at baseline and 7 hours, 1 day, 2 days, and 3 days after surgery.

Results: No significant difference in creatine kinase MB and troponin-T between HTK and blood cardioplegia groups was found at any time point. There was a significant correlation between ischemic time and markers of myocardial injury in the HTK group only and significantly more spontaneous ventricular fibrillation after release of crossclamping in the HTK group.
\end{abstract}

Conclusions: One single dose of antegrade cold HTK cardioplegic solution in elective mitral valve surgery protects the myocardium equally well as repetitive antegrade cold blood cardioplegia. (J Thorac Cardiovasc Surg 2011;141:995-1001)

Cardioplegia with histidine-tryptophan-ketoglutarate (HTKCustodiol; Koehler Chemi, Alsbach-Haenlien, Germany) or Bretschneider solution for cardiac arrest during cardiac operations has been widely used clinically and reported in more than 700,000 cases of open cardiac surgery. ${ }^{1-4}$ It is simple to use, administered as one single dose, and it is claimed to give sufficient myocardial protection for more than 2 hours of cardiac arrest. ${ }^{5,6}$ In mitral valve surgery, the procedure has to be interrupted during administration of antegrade

From the Department of Cardiothoracic Surgery, ${ }^{\text {a }}$ Oslo University Hospital Ullevål, Oslo, Norway; Department of Cardiovascular Surgery and Anesthesia, ${ }^{\mathrm{b}}$ Sahlgrenska University Hospital, Gothenburg, Sweden; Department of Molecular and Clinical Medicine, ${ }^{\mathrm{c}}$ Institute of Medicine, Sahlgrenska Academy, University of Gothenburg, Gothenburg, Sweden; and University of Oslo, ${ }^{\mathrm{d}}$ Faculty of Hospital Medicine and Center for Heart Failure Research, Oslo, Norway.

The study was supported by The Ingegerd and Viking Olov Björk Scholarship received by Professor Theis Tønnessen and by Sahlgrenska University Hospital (ALF/LUA grant). Custodiol for this study was a generous gift from NordMedica ApS, Bredgade 41, Copenhagen, Denmark.

ClinicalTrial.Gov. Protocol ID 2007-001780-30.

Disclosures: Authors have nothing to disclose with regard to commercial support.

Received for publication March 18, 2010; revisions received May 31, 2010; accepted

for publication July 5, 2010; available ahead of print Aug 30, 2010

Address for reprints: Theis Tønnessen, MD, PhD, Department of Cardiothoracic

Surgery, Oslo University Hospital Ullevål, and University of Oslo, Faculty of

Hospital Medicine, Oslo, Norway (E-mail: thto@uus.no).

$0022-5223 / \$ 36.00$

Copyright (C) 2011 by The American Association for Thoracic Surgery

doi:10.1016/j.jtcvs.2010.07.011 cardioplegia. This problem might be circumvented by using retrograde cardioplegia. However, retrograde cardioplegia might be less feasible in minimally invasive approaches, and insufficient delivery of cardioplegic solution to the right ventricle has also been claimed. ${ }^{7}$ One single dose of antegrade cardioplegia would thus be convenient in mitral valve surgery compared with the repetitive doses normally given every 20 to 30 minutes when using antegrade blood or normal crystalloid cardioplegia.

No prospective randomized studies comparing the effects of HTK and cold blood cardioplegia on myocardial injury in patients having mitral valve surgery have been reported. This is surprising given the high number of procedures performed with this cardioplegic solution. $\mathrm{We}^{8}$ have recently shown that cold blood cardioplegia gives better protection than cold crystalloid (modified St Thomas' Hospital) cardioplegia in aortic valve surgery. We therefore wanted to compare the effect of cold HTK with that of the type of cardioplegia assumed to give the best myocardial protection, namely, cold blood cardioplegia. Thus, the main aim of the present study was to examine whether one single dose of antegrade cold HTK in mitral valve surgery gives equally good myocardial protection as repetitive antegrade cold blood cardioplegia. A second aim was to examine whether the single dose of HTK results in significantly shorter crossclamp times compared with repetitive blood cardioplegia. 


\section{Abbreviations and Acronyms \\ $\mathrm{CK}=$ creatine kinase \\ HTK $=$ histidine-tryptophan-ketoglutarate}

For this purpose a prospective randomized study was performed using established markers of myocardial injury, troponin- $\mathrm{T}$ and creatine kinase isoenzyme MB (CK-MB), as end points.

\section{PATIENTS AND METHODS \\ Study Population and Design}

Between March 2007 and December 2009, 80 consecutive patients undergoing elective mitral valve surgery through a median sternotomy for mitral regurgitation at Oslo University Hospital Ullevål, Oslo, Norway, and Sahlgrenska University Hospital, Gothenburg, Sweden, were included in the study after informed written consent. The study protocol was approved by the local ethical committees. Eligible for operation were patients with mitral regurgitation equal to or larger than grade 3 of 4 . By opening of sealed envelopes, patients were randomly allocated to 1 of 2 groups before induction of anesthesia, receiving either repetitive antegrade cold $\left(4^{\circ} \mathrm{C}-\right.$ $8^{\circ} \mathrm{C}$ ) blood cardioplegic solution or one single dose of antegrade cold $\left(4^{\circ} \mathrm{C}-8^{\circ} \mathrm{C}\right)$ HTK cardioplegic solution. No additional topical cooling was used in any patient. The individual surgeon, if he believed it necessary, was free to administer additional cardioplegic solution beyond that of the protocol. In that case, however, the patient would be excluded from the study. Four male patients were excluded from the study after randomization ( 2 in each group) for the following reasons: One patient in the blood cardioplegia group was excluded because of administration of additional cardioplegic solution before scheduled by the protocol (owing to emergence of spontaneous heart rhythm after 10 minutes). Three patients, 1 in the blood cardioplegia group and 2 patients in the HTK cardioplegia group, were excluded because they received additional coronary artery bypass grafting after randomization.

Because retrograde cardioplegia given through the coronary sinus cannot always be achieved and might give inadequate protection of the right ventricle unless combined with antegrade administration of cardioplegia through the right coronary ostium, ${ }^{7}$ we decided to deliver the cardioplegic solution antegradely only, in the present study. Warm induction and reperfusion cardioplegia were not used. Cold repetitive blood cardioplegia was delivered antegradely through the ascending aorta strictly every 20 minutes with a pressure of $300 \mathrm{~mm} \mathrm{Hg}$ or less with a twin roller pump throughout the period of aortic crossclamping. Initially, after crossclamping of the aorta, a total of $900 \mathrm{~mL}$ of blood cardioplegic solution or $400 \mathrm{~mL}$ after asystole was administered. Thereafter, $500 \mathrm{~mL}$ was administered antegradely every 20 minutes, assuring that the aortic valve was competent by digital palpation of the pressure in the ascending aorta. In the group receiving HTK, approximately $1800 \mathrm{~mL}$ of solution was infused antegradely in the aorta driven by the hydrostatic pressure only (from approximately $2 \mathrm{~m}$ height) over a time span of 6 to 8 minutes as recommended by the producer. If necessary, the height of the container was adjusted to ensure that cardioplegic solution was given over the recommended time span. Serum sodium levels were controlled throughout the operation by repeated arterial blood gas samples and, when necessary, additional sodium chloride was given to maintain serum levels between 137 and $145 \mathrm{mmol} / \mathrm{l}$.

Ablation for atrial fibrillation was the only concomitant procedure that was allowed in addition to mitral valve surgery, and these patients were blockrandomized to ensure that the number of patients with ablation was equal in the 2 cardioplegia groups. Patients with any other concomitant heart valve disease or coronary artery stenoses $(\geq 50 \%)$ were excluded from the study.

\section{Anesthesia and Operative Technique}

Before intubation, the patients were given benzodiazepine (diazepam or flunitrazepam), fentanyl (3-5 $\mu \mathrm{g} / \mathrm{kg})$, thiopental $(0.5-2.0 \mathrm{mg} / \mathrm{kg})$, and cisatracurium $(0.15 \mathrm{mg} / \mathrm{kg})$ or pancuronium bromide $(0.1-0.15 \mathrm{mg} / \mathrm{kg})$. The anesthesia was continued with sevoflurane ( $1 \%-2 \%$ inspired). Under extracorporal circulation, the anesthesia was maintained with propofol (2-3 $\mathrm{mg} / \mathrm{kg}$ per hour) or midazolam $(0.02-0.04 \mathrm{mg} / \mathrm{kg})$, fentanyl $(1-2 \mu \mathrm{g} / \mathrm{kg})$, and sevoflurane ( $1 \%-2 \%$ inspired). Anticoagulation was performed with systemic heparinization and supplemented as required to maintain an activated clotting time above 480 seconds. All operations were performed using cardiopulmonary bypass with extracorporeal circulation using a roller pump, ascending aortic cannulation, double venous cannulation, and moderate systemic hypothermia $\left(32^{\circ} \mathrm{C}-34^{\circ} \mathrm{C}\right)$.

\section{Myocardial Protection}

One of the following 2 cardioplegic solutions was used for myocardial protection:

HTK solution. One liter of HTK solution (Custodiol; Koehler Chemi, Alsbach-Haenlien, Germany) contains the following components: $15 \mathrm{mmol} /$ $\mathrm{L}$ sodium chloride, $9 \mathrm{mmol} / \mathrm{L}$ potassium chloride, $4 \mathrm{mmol} / \mathrm{L}$ magnesium chloride, $18 \mathrm{mmol} / \mathrm{L}$ histidine hydrochloride, $180 \mathrm{mmol} / \mathrm{L}$ histidine, $2 \mathrm{mmol} / \mathrm{L}$ tryptophan, $30 \mathrm{mmol} / \mathrm{L}$ mannitol, $0.015 \mathrm{mmol} / \mathrm{L}$ calcium chloride, $1 \mathrm{mmol} / \mathrm{L}$ potassium hydrogen 2-ketoglutarate, osmolarity 310 $\mathrm{mOsm} / \mathrm{kg}, \mathrm{pH} 7.02-7.20$. The cardioplegic solution was delivered at a temperature of $4{ }^{\circ} \mathrm{C}-8^{\circ} \mathrm{C}$.

Blood cardioplegic solution. One liter of cold blood cardioplegic solution, mixed at a ratio of 1:4 (cardioplegic solution/blood), contains the following components: $179.1 \mathrm{mmol} / \mathrm{L}$ sodium, $22.2 \mathrm{mmol} / \mathrm{L}$ potassium, $18.6 \mathrm{mmol} / \mathrm{L}$ magnesium, $2.8 \mathrm{mmol} / \mathrm{L}$ calcium, $1.1 \mathrm{mmol} / \mathrm{L}$ procaine hydrocloride, $6.5 \mathrm{mmol} / \mathrm{L}$ acetate, $77.6 \mathrm{mmol} / \mathrm{L}$ chloride, $32.8 \mathrm{mmol} / \mathrm{L}$ hydrogen carbonate, pH 7.30-7.40. Blood cardioplegic solution may have small variations in individual variables. The cardioplegic solution was delivered at a temperature of $4^{\circ} \mathrm{C}-8^{\circ} \mathrm{C}$.

\section{Use of Inotropic Support and Postarrest Recovery Time}

Inotropic support was administered after clinical judgment by the individual anesthesiologist or cardiac surgeon mainly to keep mean arterial pressure above $60 \mathrm{~mm} \mathrm{Hg}$. No rigid protocol was established regarding inotropic support. The use of inotropic infusions longer than 20 minutes during the first 24 postoperative hours and the time from release of aortic crossclamp until weaning from extracorporeal circulation were registered.

\section{Registration of Ventricular and Atrial Fibrillation}

All patients were monitored with telemetry continuously throughout the operation and the first 3 postoperative days. A 12-lead electrocardiogram was recorded every day and compared with the electrocardiogram before the operation. All patients in whom the heart started in ventricular fibrillation after removal of the crossclamp were registered. Ventricular fibrillation was treated with $20 \mathrm{mmol}$ potassium intravenously when serum potassium was less than $5 \mathrm{mmol} / \mathrm{L}$; otherwise, internal defibrillation applying up to $20 \mathrm{~J}$ was used. Patients with episodes of atrial fibrillation postoperatively, without a history of atrial fibrillation preoperatively, were recorded.

\section{Measurements of Cardiac Marker Proteins}

Venous blood samples were collected before the operation and 7, 20, 44, and 68 hours postoperatively. The time points were chosen owing to the known profile of the enzyme release in plasma after myocardial ischemia. ${ }^{9}$ CK-MB and troponin-T were immediately analyzed as previously described. ${ }^{10}$ Serum cardiac troponin-T concentration was measured by using electrochemiluminescence immunoassay on the Roche immunoassay analyzer (Roche Diagnostics, Mannheim, Germany). The upper normal 
reference limit (99th percentile) is less than $0.10 \mathrm{ng} / \mathrm{mL}$. Serum CK-MB concentration was measured by using electrochemiluminescence immunoassay on the Roche Elecsys 2010 immunoassay analyzer. The upper normal reference limit (99th percentile) is less than $5 \mathrm{ng} / \mathrm{mL}$.

\section{Criteria for Perioperative Myocardial Infarction}

Two of the following 3 criteria had to be fulfilled to diagnose a myocardial infarction: (1) CK-MB of $100 \mu \mathrm{g} / \mathrm{L}$ or more and/or troponin- $\mathrm{T}$ of $3.0 \mu \mathrm{g} / \mathrm{L}$ or more, (2) appearance of a new postoperative $\mathrm{Q}$ wave on the electrocardiogram of more than 0.03 second, and (3) a new hypokinetic or akinetic area in the left or right ventricle by echocardiography.

\section{Statistical Analysis}

Data are presented as means \pm standard error of the mean. SigmaStat, version 3.1 (Jandel Scientific GmbH, Erkrath, Germany), was used for statistical analyses. In calculation of sample size, a $50 \%$ difference between groups regarding markers of myocardial damage was considered significant. A $50 \%$ increase would still be well below the values considered as a peroperative myocardial infarction. ${ }^{8}$ On the basis of the results of a previous study, ${ }^{11}$ a study with 80 patients would give a power of 0.97 with a $P$ value of .05 . Differences between 2 groups were analyzed by the Student $t$ test or the Mann-Whitney rank sum test for data normally and not normally distributed, respectively. Analysis of variance for repeated measures was used to compare troponin-T and CK-MB levels within and between the groups. Data not normally distributed were transformed by natural logarithm to fit a normal distribution when examining the relation between 2 continuous variables by linear regression. Comparisons of groups with dichotomous data were analyzed by Fisher's exact test or $\chi^{2}$ as appropriate.

\section{RESULTS \\ Patient Characteristics}

The characteristics of the patients are shown in Table 1. There were more women in the group receiving blood cardioplegia $(34 \%$ vs $11 \% ; P=.03)$. There was no difference in crossclamp time between the blood cardioplegia group and the HTK group (73 \pm 3 vs $75 \pm 3$ minutes; $P=.81)$. Furthermore, no significant differences in the frequency of myocardial infarction, inotropic support, artial fibrillation, or 30-day mortality were found between the 2 types of cardioplegia. There were no significant differences in body weight and body surface area between the 2 groups (Table 1).

After removal of the aortic crossclamp, there was a significant difference between the 2 groups of patients regarding spontaneous ventricular fibrillation. Twenty-seven $(71 \%)$ of 38 patients receiving HTK resumed cardiac activity after ischemia in ventricular fibrillation compared with

TABLE 1. Patient characteristics (mean \pm SEM)

\begin{tabular}{|c|c|c|c|}
\hline Characteristics & $\begin{array}{c}\text { Blood } \\
\text { cardioplegia }\end{array}$ & $\begin{array}{c}\text { HTK } \\
\text { cardioplegia }\end{array}$ & $P$ value \\
\hline $\mathrm{N}$ & 38 & 38 & \\
\hline Age (y) & $59 \pm 2$ & $59 \pm 2$ & .98 \\
\hline Females (no.) & $13(34 \%)$ & $4(11 \%)$ & .03 \\
\hline Body weight (kg) & $80 \pm 2$ & $86 \pm 3$ & .10 \\
\hline Body surface area $\left(\mathrm{m}^{2}\right)$ & $1.98 \pm 0.03$ & $2.06 \pm 0.04$ & .12 \\
\hline Mitral valve repair & $33(87 \%)$ & $34(89 \%)$ & 1 \\
\hline Mitral valve replacement & $5(13 \%)$ & $4(11 \%)$ & 1 \\
\hline AF ablation perop. & $4(11 \%)$ & $6(16 \%)$ & .73 \\
\hline Ex.corp.circ. $(\min )$ & $103 \pm 3$ & $107 \pm 4$ & .55 \\
\hline X-clamp (min) & $73 \pm 3$ & $75 \pm 3$ & .81 \\
\hline Postarrest recovery (min) & $21 \pm 1$ & $20 \pm 1$ & .60 \\
\hline Hemoglobin at max CK-MB $(\mathrm{g} / \mathrm{L})$ & $11.0 \pm 0.2$ & $11.5 \pm 0.2$ & .10 \\
\hline Hemoglobin at max. troponin- $\mathrm{T}(\mathrm{g} / \mathrm{L})$ & $11.0 \pm 0.2$ & $11.4 \pm 0.2$ & .12 \\
\hline Creatinine preop. $(\mu \mathrm{mol} / \mathrm{L})$ & $78 \pm 3$ & $81 \pm 2$ & .15 \\
\hline Creatinine $48 \mathrm{~h}$ postop. $(\mu \mathrm{mol} / \mathrm{L})$ & $76 \pm 5$ & $75 \pm 3$ & .28 \\
\hline Postop. inotropic infusion $>20 \min$ (no.) & $7(18 \%)$ & $10(27 \%)$ & .54 \\
\hline Postop. AF. (no.) & $12(32 \%)$ & $8(21 \%)$ & .44 \\
\hline Thirty-day mortality (no.) & 0 & 0 & \\
\hline Myocardial infarction (no.) & 0 & 0 & \\
\hline Preop. EF $\geq 50$ (no.) & $36(95 \%)$ & $33(87 \%)$ & .43 \\
\hline Preop. use of beta-blockers (no.) & $12(32 \%)$ & $11(29 \%)$ & 1 \\
\hline Postop. use of beta-blockers (no.) & $20(54 \%)$ & $18(49 \%)$ & .82 \\
\hline Ventricular fibrillation after X-clamp removal (no.) & $5(13 \%)$ & $27(71 \%)$ & $<.001$ \\
\hline Internal defib. after X-clamp removal (no.) & $3(8 \%)$ & $12(32 \%)$ & .02 \\
\hline Amounts of cardioplegic solution (mL) & $1954 \pm 65$ & $1794 \pm 10$ & .05 \\
\hline Postop red blood cell transfusion (no.) & $8(21 \%)$ & $5(13 \%)$ & .54 \\
\hline Lowest core temp. under ex.corp.circ $\left({ }^{\circ} \mathrm{C}\right)$ & $33.4 \pm 0.2$ & $33.5 \pm 0.2$ & .78 \\
\hline
\end{tabular}

$\overline{S E M}$, Standard error of the mean; $H T K$, histidine-tryptophan-ketoglutarate; $A F$, atrial fibrillation; Ex.corp.circ, extracorporeal circulation; $X$-clamp, crossclamp; $C K$ - $M B$, creatine kinase isoenzyme MB; Perop, peroperatively; Postop, postoperatively; EF, ejection fraction; Defib., defibrillation; no., number of patients; Temp., temperature. 



FIGURE 1. A, Maximum postoperative CK-MB with blood and HTK cardioplegia $(P=.80)$. B, Maximum postoperative troponin- $\mathrm{T}$ with blood and HTK cardioplegia $(P=.60)$. Values are mean \pm standard error of the mean. $C K-M B$, Creatine kinase isoenzyme MB; $H T K$, histidine-tryptophan-ketoglutarate.

$5(13 \%)$ of 38 in the group receiving cold blood cardioplegia $(P<.001)$.

\section{CK-MB}

Maximum CK-MB did not differ between the HTK group and the blood cardioplegia group $(56.2 \pm 4.7$ vs $55.9 \pm$ $4.9 \mu \mathrm{g} / \mathrm{L} ; P=.80$; Figure $1, A)$. The highest value was measured 7 hours postoperatively (Figure 2, A). Furthermore, there were no significant differences in CK-MB levels between groups at any postoperative time point $(P=.65$, between groups). A significant correlation between ischemic time and CK-MB was found in the HTK group (Figure 3, $C$ ) but not in the blood cardioplegia group (Figure 3, $A$ ). There was, however, no significant difference in the correlations when compared between groups $(P=.49)$. There was no significant difference in maximum CK-MB levels between patients with or without postoperative ventricular fibrillation after removal of the aortic crossclamp $(P=.92)$, between patients with $(\mathrm{n}=15)$ and without $(\mathrm{n}=61)$ internal defibrillation $(P=.47)$, or between men and women $(P=.20)$.



FIGURE 2. A, Creatine kinase isoenzyme MB preoperatively and 7, 20, 44 , and 68 hours postoperatively ( $P=.65$ between groups). B, TroponinT preoperatively and $7,20,44$, and 68 hours postoperatively $(P=.30$ between groups). Values are mean \pm standard error of the mean. $C K-M B$, Creatine kinase isoenzyme MB; HTK, histidine-tryptophan-ketoglutarate; Preop, preoperatively; $P O$, postoperatively.

\section{Troponin-T}

Maximum troponin-T did not differ significantly between the HTK group and the blood cardioplegia group $(1.13 \pm 0.12$ vs $1.05 \pm 0.11 \mu \mathrm{g} / \mathrm{L} ; P=.60$; Figure $1, B)$. In accordance with CK-MB, the highest troponin-T value was found in the first blood sample 7 hours after the operation (Figure 2, B). There were no significant differences in troponin-T levels between the groups at any postoperative time point ( $P=.30$, between groups). A significant correlation between time of ischemia and troponin- $T$ was found in the HTK group (Figure 3,D) whereas this correlation did not reach the level of significance in the blood cardioplegia group (Figure 3, B). Again, there was no significant difference in the correlations when compared between groups $(P=.95)$. There was no significant difference in maximum postoperative release of troponin-T between patients with or without postoperative ventricular fibrillation after removal of the aortic crossclamp $(P=.50)$, between patients 


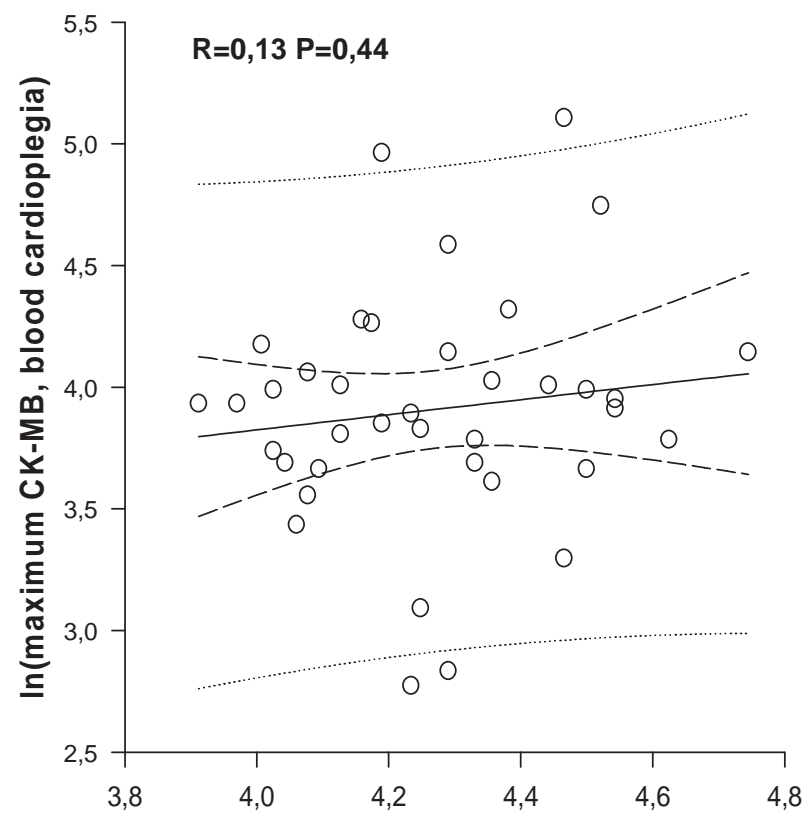

A



C In(cross-clamp time, HTK cardioplegia)


D

FIGURE 3. A and B, No correlation between cardiac enzymes and crossclamp time in the group of patients receiving cold blood cardioplegia. C and D, Positive correlation between cardiac enzymes and crossclamp time in the group of patients receiving HTK cardioplegia. Dashed lines show $95 \%$ confidence and prediction intervals. $C K-M B$, Creatine kinase isoenzyme $\mathrm{MB}$; $H T K$, histidine-tryptophan-ketoglutarate.

defibrillated or not $(P=.93)$, or between men and women $(P=.38)$.

\section{DISCUSSION}

This prospective, randomized study shows that one single antegrade dose of cold HTK cardioplegia gives a cardioprotective effect comparable with that of repeated doses of antegrade cold blood cardioplegia in patients operated on for elective mitral valve regurgitation when using CK-MB and troponin- $\mathrm{T}$ as measures of myocardial injury. There was a significant correlation between crossclamp time and cardiac enzymes in the HTK group, but not in the group receiving blood cardioplegia. Crossclamp time was not significantly different between the 2 groups. Significantly higher 
rates of ventricular fibrillation after removing the aortic crossclamp were observed in the group of patients receiving HTK, although this did not influence cardiac enzyme release.

HTK is an intracellular cardioplegic solution containing low sodium concentration to arrest the heart by inhibiting the rapid phase of the action potential, histidine as buffer, ketoglutarate to improve the ATP energy production during reperfusion, tryptophan to stabilize the cell membrane, and mannitol to decrease the cellular edema. ${ }^{12-15}$ Because of these qualities and the high buffer capacity, it has been demonstrated that one single dose of HTK is sufficient for myocardial protection up to more than 2 hours of ischemia. ${ }^{6}$ The solution is also frequently used for organ preservation in solid organ transplantation with longstanding ischemia. ${ }^{16}$ Although HTK has been used for several years in Germany under the name of Bretschneider solution, HTK solution, or Custodiol, ${ }^{17}$ there are few studies comparing the effect with other widely established types of cardioplegia.

In mitral valve surgery, the retractor normally used has to be dismounted during administration of antegrade cardioplegia to ensure competence of the aortic valve and proper delivery to the coronary arteries. Retrograde cardioplegia might be applied to circumvent this problem; however, it cannot always be achieved as, for example, in minimally invasive approaches. Moreover, insufficient delivery of cardioplegic solution to the right ventricle has been claimed unless supplemented with cardioplegic solution delivered through the right coronary ostium. ${ }^{7}$ Thus, one single dose of cardioplegic solution would be especially attractive in mitral valve surgery compared with the repetitive doses normally given every 20 to 30 minutes when using blood and normal crystalloid cardioplegia. This latter procedure might interrupt mitral valve surgery several times per procedure. Since blood cardioplegia is frequently used and believed to give better myocardial protection than crystalloid cardioplegia, ${ }^{8}$ we compared the effect of HTK with that of blood cardioplegia on myocardial injury. The average crossclamp time in the present study was just above 70 minutes in both groups. There was no difference in the release of the cardiac enzymes CK-MB and troponin- $\mathrm{T}$, although there was more spontaneous ventricular fibrillation in the HTK group. Because of the relatively short crossclamp times in the present study, there was no difference in crossclamp time between groups, although one would expect a somewhat shorter crossclamp time in favor of HTK in more complex and longer lasting procedures. The reason for this finding, although HTK is only given as one single dose, is most likely that the initial time of HTK administration is between 6 and 8 minutes and thus longer than for blood cardioplegia.

Although no differences in myocardial enzyme release between HTK and blood cardioplegia could be demonstrated in the present study, experimental studies comparing multidose cold blood cardioplegia ${ }^{18}$ or multidose cold St Thomas ${ }^{6}$ Hospital solution ${ }^{12}$ with one single dose of cold
HTK have reported that HTK provides less adequate cardioprotection. Both studies applied 60 minutes of crossclamping, which is comparable with our study, but they reported almost double values of troponin- $T$ in the groups receiving HTK, and in the study by Aarsæther and coworkers, ${ }^{12} 5$ of 12 pigs could not be weaned from cardiopulmonary bypass. In the study by Fanneløp and coworkers ${ }^{18} 4$ animals were excluded owing to persistent therapy-resistant arrhythmias. This was clearly not the result in patients, leading us to speculate that species differences and the known fragility of the pig model might explain the differences between those studies and the present. Taken together, although we did not observe any differences in myocardial damage between groups in the present study, further studies are needed to document the safety of one dose of HTK in crossclamp times exceeding those of the present study.

Clinically, surprisingly few prospective randomized studies have been performed with HTK solution as cardioprotection. Most studies have been performed on patients undergoing coronary artery bypass grafting and only a relatively small number of patients have been included. We have not been able to find any prospective randomized studies comparing multidose cold blood with single-dose HTK cardioplegia in mitral valve surgery. One retrospective study with a total of 46 patients undergoing mitral valve replacement with various additional procedures (bypass grafting, maze, tricuspid valve surgery) ${ }^{19}$ reported in accordance with the present study more spontaneous ventricular fibrillation after removal of the crossclamp in patients receiving HTK. CK-MB and troponin-T were not measured and crossclamp time was 20 minutes longer in the HTK group. Moreover, the temperature of the cardioplegic solution given was $15^{\circ} \mathrm{C}$ in blood compared twith $4^{\circ} \mathrm{C}$ in the HTK solution, making a comparison of the 2 cardioplegic solutions difficult. In another small study ${ }^{20}$ reporting on 8 patients receiving HTK cardioplegia only for minimally invasive mitral valve surgery, it was concluded that HTK solution provides safe long cardioplegic arrest time. Studies including patients with other types of open cardiac operations have reported various results. ${ }^{21,22}$

A significant increase in spontaneous ventricular fibrillation after crossclamp removal in the group of patients receiving HTK was demonstrated in the present study. An increase in fibrillation after crossclamp removal has been linked to conduction disturbances associated with inadequate intraoperative myocardial protection caused by heterogeneous reperfusion, oxidative stress, and alteration of electrolyte concentration across the cell membranes and low adenosine triphosphate levels. ${ }^{23-27}$ However, the most sensitive and specific markers of myocardial injury in clinical use, troponin-T and CK-MB, did not show any differences between groups in our study.

This study has some potential limitations. Although there is a potential possibility of a type II statistical error, 
statistical calculations a priori should rule this out with a $97 \%$ probability. There were more women in the blood cardioplegia group. There was, however, no difference in cardiac enzymes between men and women in the present study and therefore this does not influence on our conclusion. Ablation for atrial fibrillation was not an exclusion criterion and may potentially influence troponin-T and CK-MB levels. There was, however, no significant difference in the number of patients receiving ablation in each group. Also, mitral valve repair or replacement might play a potential role regarding release of cardiac enzymes. These procedures were also equally distributed between groups and should therefore not influence the conclusion. The correlation between crossclamp time and cardiac enzymes in the HTK group was significantly different, but there was no significant difference when these correlations were compared with the same correlations in the blood cardioplegia group. Thus, the correlations in the HTK group should be interpreted with caution because of the limited number of observations.

In conclusion, one single dose of antegrade cold HTK cardioplegia in elective mitral valve surgery is as effective as repetitive antegrade cold blood cardioplegia in protecting the myocardium, as measured by CK-MB and troponin-T. No difference in crossclamp time was found. There was more spontaneous ventricular fibrillation in the HTK group after crossclamp removal, although the level of cardiac enzymes was not different between groups. HTK cardioplegia is simpler to use than blood cardioplegia in mitral valve surgery because the operation can be performed continuously without interruptions, for up to 2 hours of ischemia, provided no coronary artery stenoses are present and moderate hypothermia of the patient is used.

We thank the staff of the Department of Cardiothoracic Surgery and the Department of Cardiothoracic Anesthesiology, Oslo University Hospital Ullevål, Norway, and Sahlgrenska University Hospital, Gothenburg, Sweden, for helping to perform the study. We also thank Ståle Nygård for valuable advice regarding statistical analyses.

\section{References}

1. Gallandat Huet RC, Karliczek GF, van der Heide JN, Brenken U, Mooi B, van der Broeke JJ, et al. Clinical effect of Bretschneider-HTK and St. Thomas cardioplegia on hemodynamic performance after bypass measured using an automatic datalogging database system. Thorac Cardiovasc Surg. 1988;36:151-6.

2. Remadi JP, Baron O, Roussel C, Bizouarn P, Habasch A, Despins P, et al. Isolated mitral valve replacement with St Jude Medical prosthesis: long-term results: a follow-up of 19 years. Circulation. 2001;103:1542-5.

3. Mehlhorn U, Sauer H, Kuhn-Regnier F, Sudkamp M, Dhein S, Eberhardt F, et al. Myocardial beta-blockade as an alternative to cardioplegic arrest during coronary artery surgery. Cardiovasc Surg. 1999;7:549-57.

4. Salvador L, Mirone S, Bianchini R, Regesta T, Patelli F, Minniti G, et al. A 20year experience with mitral valve repair with artificial chordae in 608 patients. J Thorac Cardiovasc Surg. 2008;135:1280-7.
5. Gebhard MM, Preusse CJ, Schnabel PA, Bretschneider HJ. Different effects of cardioplegic solution HTK during single or intermittent administration. Thorac Cardiovasc Surg. 1984;32:271-6.

6. Liu J, Feng Z, Zhao J, Li B, Long C. The myocardial protection of HTK cardioplegic solution on the long-term ischemic period in pediatric heart surgery. ASAIO J. 2008;54:470-3.

7. Allen BS, Winkelmann JW, Hanafy H, Hartz RS, Bolling KS, Ham J, et al. Retrograde cardioplegia does not adequately perfuse the right ventricle. $J$ Thorac Cardiovasc Surg. 1995;109:1116-24.

8. Braathen B, Tønnessen T. Cold blood cardioplegia reduces the increase in cardiac enzyme levels compared with cold crystalloid cardioplegia in patients undergoing aortic valve replacement for isolated aortic stenosis. J Thorac Cardiovasc Surg. 2010;139:874-80.

9. Januzzi JL, Lewandrowski K, MacGillivray TE, Newell JB, Kathiresan S, Servoss SJ, et al. A comparison of cardiac troponin $\mathrm{T}$ and creatine kinase-MB for patient evaluation after cardiac surgery. J Am Coll Cardiol. 2002;39:1518-23.

10. Larstorp AC, Lund SC, Tønnessen T, Muller C, Kjeldsen SE, Mangschau A. Scintigraphic demonstration of myocardial perfusion and ischaemia associated with coronary artery bypass grafting. Scand Cardiovasc J. 2006;40:354-62.

11. Braathen B, Vengen OA, Tønnessen T. Myocardial cooling with ice-slush provides no cardioprotective effects in aortic valve replacement. Scand Cardiovasc J. 2006;40:368-73.

12. Aarsæther E, Stenberg TA, Jakobsen O, Busund R. Mechanoenergetic function and troponin $\mathrm{T}$ release following cardioplegic arrest induced by St Thomas' and histidine-tryptophan-ketoglutarate cardioplegia-an experimental comparative study in pigs. Interact Cardiovasc Thorac Surg. 2009;9:635-9.

13. Bretschneider HJ. Myocardial protection. Thorac Cardiovasc Surg. 1980;28: 295-302.

14. Preusse CJ, Winter J, Schulte HD, Bircks W. Energy demand of cardioplegically perfused human hearts. J Cardiovasc Surg (Torino). 1985;26:558-63.

15. Preusse CJ, Gebhard MM, Bretschneider HJ. Myocardial "equilibration processes" and myocardial energy turnover during initiation of artificial cardiac arrest with cardioplegic solution-reasons for a sufficiently long cardioplegic perfusion. Thorac Cardiovasc Surg. 1981;29:71-6.

16. Fridell JA, Mangus RS, Tector AJ. Clinical experience with histidine-tryptophanketoglutarate solution in abdominal organ preservation: a review of recent literature. Clin Transplant. 2009;23:305-12.

17. Beyersdorf F, Krause E, Sarai K, Sieber B, Deutschlander N, Zimmer G, et al Clinical evaluation of hypothermic ventricular fibrillation, multi-dose blood cardioplegia, and single-dose Bretschneider cardioplegia in coronary surgery. Thorac Cardiovasc Surg. 1990;38:20-9.

18. Fanneløp T, Dahle GO, Salminen PR, Moen CA, Matre K, Mongstad A, et al. Multidose cold oxygenated blood is superior to a single dose of Bretschneider HTK-cardioplegia in the pig. Ann Thorac Surg. 2009;87:1205-13.

19. Sakata J, Morishita K, Ito T, Koshino T, Kazui T, Abe T. Comparison of clinical outcome between histidine-triptophan-ketoglutalate solution and cold blood cardioplegic solution in mitral valve replacement. J Card Surg. 1998;13:43-7.

20. Savini C, Camurri N, Castelli A, Dell'Amore A, Pacini D, Suarez SM, et al. Myocardial protection using HTK solution in minimally invasive mitral valve surgery. Heart Surg Forum. 2005;8:E25-7.

21. Arslan A, Sezgin A, Gultekin B, Ozkan S, Akay T, Uguz E, et al. Low-dose histidine-tryptophan-ketoglutarate solution for myocardial protection. Transplant Proc. 2005;37:3219-22.

22. Careaga G, Salazar D, Tellez S, Sanchez O, Borrayo G, Arguero R. Clinical impact of histidine-ketoglutarate-tryptophan (HTK) cardioplegic solution on the perioperative period in open heart surgery patients. Arch Med Res. 2001;32:296-9.

23. Manning AS, Hearse DJ. Reperfusion-induced arrhythmias: mechanisms and prevention. J Mol Cell Cardiol. 1984;16:497-518.

24. Holman WL, Spruell RD, Vicente WV, Pacifico AD. Electrophysiological mechanisms for postcardioplegia reperfusion ventricular fibrillation. Circulation. 1994; 90(5 Pt 2):II293-8.

25. Gorlach G, Podzuweit T, Borsutzky B, Lohmann E, Dapper F. Factors determining ventricular fibrillation after induced cardiac arrest. Thorac Cardiovasc Surg. 1991;39:140-2.

26. Murrah CP, Ferguson ER, Spruell RD, Holman WL. Arrest duration influences postcardioplegia electrophysiologic recovery and reperfusion arrhythmias. Ann Thorac Surg. 1998;65:1003-8.

27. Sellevold OF, Berg EM, Levang OW. Procaine is effective for minimizing postischemic ventricular fibrillation in cardiac surgery. Anesth Analg. 1995;81:932-8. 